\title{
CRÍTICA COMPARADA E CULTURAL
}

\author{
Eneida Maria de Souza \\ Universidade Federal de Minas Gerais
}

\begin{abstract}
Resumo: Este ensaio pretende refletir sobre a situação do discurso crítico brasileiro dos últimos anos e sua importância para o avanço da crítica comparada e cultural na América Latina. Discute a questão disciplinar e a diferença produzida pelos discursos dos países periféricos como resposta a projetos hegemônicos. Como corpus de análise a escolha recaiu no filme mexicano Babel.
\end{abstract}

Palavras-chave: literatura comparada; crítica cultural; filme Babel

Resumen:Este ensayo pretende reflexionar sobre la situación del discurso crítico brasileño de los últimos años y su importancia para el avance de la crítica comparada y cultural en América Latina. Discute la cuestión disciplinar y la diferencia producida por los discursos de los países periféricos como respuesta a los proyectos hegemónicos. Como corpus de análisis la elección recayó en la película mexicana Babel.

Palabras clave: literatura comparada; crítica cultural; película Babel

Refletir sobre a situação do discurso crítico brasileiro dos últimos anos, a par de sua importância para a legitimação do avanço da crítica comparada e cultural em ritmo latino, constitui empresa de extrema necessidade. Contextualizar o trajeto e a transformação desse discurso crítico exige do pesquisador discernimento e imparcialidade, observação atenciosa a respeito das causas da procedência de teorias ou de conceitos que mais se sobressaíram nesta ou em outra época. Acusar nesse discurso a proliferação excessiva de termos e metodologias como efeito de moda acadêmica ou universitária, de cópia de modelos importados sem relação efetiva com o contexto crítico da recepção constitui um dos mais freqüentes reparos recebidos pela crítica contemporânea. No entanto, esses reparos se mostram, na maioria das vezes, contaminados por uma posição conservadora e passadista diante do espírito de inovação e mudança da crítica literária e cultural mais experimentalista.

Prevalece ainda no âmbito das realizações de eventos literários ou de outra natureza a ausência de um programa que seja ao mesmo tempo celebratório e crítico, ao indicar ganhos teóricos e empecilhos metodológicos causados por limitações de ordem ideológica ou temporal. Esse escrúpulo analítico concorre apenas para o fortalecimento da relação entre saber e poder dos discursos institucionais, impedindo o acesso a vozes dissonantes e reforçando a estrutura parasitária da academia, na qual o passado se impõe como solução e resposta para os embates do presente.

\section{Teorias sem disciplina}

Torna-se quase impossível desvincular a análise da crítica comparada e cultural dos últimos dez anos dos programas desenvolvidos em muitas universidades nacionais e estrangeiras; dos congressos realizados pela Abralic, a ANPOLL e outras associações literárias; dos convidados escolhidos para abrir o debate de cada programação; do projeto de tradução de autores representativos dessa disciplina principalmente pelas editoras universitárias; de programas internacionais de publicação de autores latinoamericanos, como a "Coleção Vereda Brasil", na Argentina, assim como os convênios 
institucionais entre o Brasil e o exterior. Esses fatores são significativos para o mapeamento da crítica cultural no Brasil e sua relação com teóricos da América Latina e de universidades americanas, bem como para a abertura de questões disciplinares, envolvendo a literatura comparada e os estudos culturais, a gradativa transformação de um sistema disciplinar para o pós-disciplinar, no qual é possível conviver com a diluição dos campos de saber. Representantes da crítica comparada e cultural - ou eleitos pela crítica dentro dessa rubrica - transitam livremente nas áreas de crítica literária, antropologia, filosofia, história ou comunicação -, o que impede a presença de uma hierarquização rígida das disciplinas e o fechamento de cada área por meio de uma especificidade restrita. A gradativa abertura do campo disciplinário autorizou $o$ questionamento e a desconstrução do saber moderno, pautado por classificações hierárquicas, por seleções excludentes dos saberes considerados "menores", além da desconfiança diante de rótulos disciplinares, dotados de rigor e estabilidade conceitual. A década de 1990 é responsável pela expansão globalizante da tecnologia, da comunicação mais rápida entre os pares, do aumento ao acesso a uma bibliografia atualizada produzida nas instituições estrangeiras, assim como da redefinição do conceito de cultura, não mais limitado ao padrão letrado. Esses fatores coincidiram com o parcial esfacelamento das instituições públicas, gerando desemprego, aposentadorias precoces e desencanto da classe universitária diante das mudanças impostas pela nova ordem neoliberal. Com o esvaziamento do quadro docente das universidades públicas, transferiu-se o capital simbólico para a rede privada, que acolheu, sem nenhum gasto, profissionais de alta qualificação e experiência acadêmicas. O deslocamento dos saberes se efetua ainda nessa passagem, em que se questionam princípios e valores que, na prática, recebem tratamento distinto, como a fragilidade dos conceitos, a instabilidade das certezas, o mercantilismo do conhecimento e a competição mais acirrada pelo bem privado. A defesa dos ideais acadêmicos e dos valores profissionais sofre um de seus maiores abalos desde a ditadura militar, comprometendo, sem dúvida, o sistema de referências teóricas e metodológicas das disciplinas.

Constata-se igualmente a presença de uma geração nova de doutores e doutorandos que, embora estejam bem qualificados para o exercício profissional, têm de optar por atividades muitas vezes alternativas, como a produção de revistas, a revisão de textos, a procura de empregos no exterior, ou se entregam à migração, de forma insegura, de uma instituição a outra, sujeitando-se ao jogo competitivo e mercantilista do poder privado. Com a carência de oportunidades de trabalho na sociedade atual, criam-se novos espaços de enunciação, revertendo em ganho para a caracterização dos estudos culturais como "formações discursivas", na feliz expressão de Stuart Hall. A flexibilização dos espaços institucionais público e privado permitiu tanto a conservação de quadros profissionais, com o retorno à universidade pública dos aposentados, quanto à renovação da instituição privada por egressos do serviço público. Renovação esta que desloca saberes, mas que reprime a entrada dos jovens na vida acadêmica, o que resulta em perda do sentido de cidadania e ética profissionais. Como se percebe, os princípios defendidos pela crítica comparada e cultural, como a flexibilização disciplinar, a precariedade dos saberes e a diluição de hierarquias diante do conhecimento influenciam o comportamento dos sujeitos, que passam a interpretar esses princípios ao pé da letra. Mas se as regras hierárquicas são atenuadas no momento em que mestres e alunos se vêem em igualdade de condição para prestar concursos e provas, elas são revertidas quando se torna necessário medir e pesar as diferenças.

Dentro desse quadro de falência institucional, nada mais oportuno que o surgimento de polêmicas que estavam diretamente relacionadas ao estatuto da crítica literária e o seu desdobramento em crítica cultural, afetando, ainda, os princípios 
básicos da literatura comparada como disciplina, além de obscurecer seu objeto de estudo. Um dos fatores que mais contribuíram para o acirramento do debate foi a necessidade de politização dos saberes, da defesa de espaços discursivos pelas minorias, espaços esses que coincidiam com a defesa de postos acadêmicos. No âmbito mais restrito das faculdades de letras, a oficialização da literatura comparada como curso de pós-graduação foi motivo de polêmica por parte das literaturas nacionais (principalmente brasileira), que se viam ameaçadas pelo fortalecimento da abertura transdisciplinar e pela inserção do literário na rede internacional dos discursos.

A polêmica teve como palco inicial a discussão entre pesquisadores no $V$ Congresso Abralic de 1996, realizado no Rio de Janeiro, tendo sido oficializada em 1998, no VI Congresso de Santa Catarina, cujo tema motivava o debate: "Literatura Comparada = Estudos Culturais?"1 Não pretendo retomar aqui a discussão, uma vez que o tema não só é do conhecimento da maioria, mas por entender que hoje a questão ultrapassa os limites disciplinares e se abre para outros interesses. O mais importante é procurar entender as razões ocultas da polêmica, com vistas a obter avanços teóricos no lugar de retrocessos. A comunicação apresentada por Eneida Leal Cunha nesse Congresso de 1998, intitulada "Literatura Comparada \& Estudos Culturais: ímpetos pós-disciplinares", ao se apoiar em texto de Fredric Jameson sobre os estudos culturais, acata o seu estatuto pós-disciplinar, além da recusa em definir diferenças ou semelhanças entre literatura comparada e estudos culturais. Embora acredite que "muito do que se tem produzido na nossa peculiar Literatura Comparada, submete-se explicitamente ao rótulo de Estudos Culturais", tal afirmação não lhes assegura um papel pós-disciplinar: "É nessa clave da pós-disciplinaridade que pretendo desfazer e refazer a equação que suspeita ou insinua a igualdade, examinando que aproximações e diferenciações são possíveis entre os Estudos Culturais e a nossa (é importante grifar), daqui e de agora, Literatura Comparada: pondo um close sobre as possíveis significações e implicações do termo pós-disciplinar ao lado de uma panorâmica da produção crítica brasileira que se tem abrigado sob o rótulo de Literatura Comparada."2

Acrescentaria a esse texto que o motivo determinante da preocupação em definir campos disciplinares e distinguir especificidades pertence à ordem do cogito moderno, da classificação seletiva e hierárquica das disciplinas. A reflexão da ensaísta, após alguns anos de enunciada, é claramente perceptível nos dias atuais, em que se delineia uma tendência nitidamente pós-disciplinar. Tanto a literatura comparada quanto os estudos culturais - e mais especificamente a crítica cultural - não se definem mais como campos disciplinares definidos e estáveis. "Teorías sin disciplina", título referente ao projeto apresentado pelo "Grupo Latinoamericano de Estudos Subalternos", tendo Santiago Castro-Gomez como um dos membros, poderia ser uma das saídas para a complexa discussão sobre o campo disciplinar contemporâneo. O trânsito das teorias, a contaminação salutar de conceitos de várias disciplinas, a elasticidade e tolerância das fronteiras textuais, seria ilusória e impossível se pensar numa situação epistemológica dessa natureza?

No entanto, vários motivos dificultam a perfeita atualização desses propósitos, quando as disciplinas, ao serem inseridas no currículo acadêmico, se institucionalizam,

\footnotetext{
${ }^{1}$ Cf. os artigos de minha autoria: "O não-lugar da literatura", "A teoria em crise", inseridos em SOUZA, Eneida Maria de. Crítica cult. Belo Horizonte: Editora UFMG, 2002; MIRANDA, Wander Melo. "Projeções de um debate." Revista Brasileira de Literatura Comparada. Florianópolis, 1998, n.4; SCHMIDT, Rita. "Disputas e impasses no campo minado." Revista Travessia. UFSC, Florianópolis, n.38, jan. /jun.1999.

${ }^{2}$ CUNHA, Eneida Leal. "Literatura Comparada \& Estudos Culturais: ímpetos pós-disciplinares". In: ANDRADE, A. L.; CAMARGO, M.L.; ANTELO, R.. Leituras do ciclo. Chapecó: Grifos, Abralic, 1999.p. 101.
} 
no mau sentido da palavra, e se revestem de autoritarismo e fechamento. Reinaldo Marques, no artigo "Literatura Comparada e estudos culturais: diálogos interdisciplinares", reproduz o sentimento de temor de Stuart Hall diante da institucionalização rápida e galopante dos estudos culturais realizada na academia americana - diferentemente do que se verificou na Inglaterra e também no Brasil - e acredita estarmos vivendo uma época pós-disciplinar: ${ }^{3}$ A defesa deliberada do espaço disciplinar na academia contraria os pressupostos que regem a crítica cultural, ao se desvincular de toda e qualquer ambição de propriedade e de domínio sobre outros campos: "Pode ser que assim proceda ao levar em conta, e com muita razão, aquela formulação de Hall que vê na institucionalização dos estudos culturais "um momento de profundo perigo". Pode ser até que, com o fim dos saberes disciplinares e a presente crise dos paradigmas científicos, o que está se delineando à nossa frente seja mesmo um mundo pós-disciplinar". ${ }^{4}$

No Brasil, é inegável que o avanço dos estudos de literatura comparada é tributário das iniciativas de ordem institucional, como a criação de cursos de pósgraduação e da Associação Brasileira de Literatura Comparada (Abralic), em 1988. É necessário assinalar que, à exceção da USP, os cursos de pós-graduação nessa disciplina tenham se iniciado na década de 1980, descortinando o campo interdisciplinar de forma até então inexistente, além de promover uma reflexão mais aprofundada das teorias importadas e de sua efetiva recepção. Curiosamente, os estudos culturais nos Estados Unidos vão surgir nessa época, como atesta George Yúdice em conferência proferida em Salvador durante o "Encontro de Literatura Comparada da ANPOLL", em 1997. O crítico assim se expressa: " Acredito que posso localizar com precisão o momento que surge esse tipo de reflexão teórica. Seria no final dos anos 70, e é detectável no primeiro número da revista Social Text. Essa revista nasceu da colaboração de duas figuras destacadas da esquerda acadêmica estadunidense: Fredric Jameson e Stanley Aronowitz. O primeiro tinha longa experiência com a teoria crítica, o marxismo francês e o pósestruturalismo. O outro trabalhou dentro das filas dos movimentos sociais estadunidenses.(...) Com Jameson e Aronowitz e outros que já tinham assimilado o novo instrumental teórico, operou-se uma transformação epistemológica. Estética, mediação, ideologia, inconsciente e consumo constituíram uma sinergia crítica, como para os frankfurtianos, mas ainda com mais poder analítico, devido à introdução de novas perspectivas derivadas da categoria de gênero, provido pelo feminismo, e do suplemento, suprido pelo desconstrucionismo derridiano". 5

Por essa coincidência temporal, torna-se justificável a recepção, em algumas instituições brasileiras, de textos significativos de crítica cultural, notadamente em razão do convite feito a professores estrangeiros para participar dos encontros e congressos da Associação. Pelo fato da não coincidência entre os rótulos disciplinares, a literatura

\footnotetext{
3 “Contudo, devo dizer, enfaticamente, que me faz lembrar a forma como, na Inglaterra, encaramos sempre a institucionalização como um momento profundamente perigoso. Tenho dito que os perigos não constituem lugares dos quais se pode fugir, mas lugares para onde se vai. Portanto, queria apenas que soubessem que minha opinião pessoal é que a explosão dos estudos culturais, juntamente com outras formas de teoria crítica na academia, representa um momento de perigo extraordinário.'HALL, Stuart. Estudos culturais e seu legado histórico. In: Da diáspora. Identidades e mediações culturais. Org. Liv Sovik. Belo Horizonte: Editora UFMG, 2003. p. 215.

${ }^{4}$ MARQUES, Reinaldo. Literatura Comparada e Estudos Culturais: diálogos interdisciplinares. In; CARVALHAL, Tânia Franco (org.). Culturas, contextos e discursos: limiares críticos do comparatismo. Porto Alegre: Editora da Universidade/UFRGS, 1999. p.58-67.
}

${ }^{5}$ YÚDICE, George. Debates atuais em torno dos estudos culturais nos Estados Unidos. Texto impresso. Set. 1997, p. 4. 
comparada foi se mesclando aos princípios e objetivos da crítica cultural, desde o momento em que se processa o seu revigoramento no Brasil, considerando-se o diálogo iniciado por pesquisadores nacionais com a academia americana. Em outra ocasião já havia discorrido sobre as razões da retomada dos estudos comparados nas instituições brasileiras, como a abertura política, o fortalecimento dos discursos minoritários e a necessidade de estabelecer relações tanto interdisciplinares quanto de ordem internacional. ${ }^{6}$ Novas orientações começam a surgir, deslocando-se a bibliografia tradicional de literatura comparada segundo o modelo europeu, para outra vertente mais condizente com o pós-estruturalismo francês e a releitura política operada por teóricos americanos e latino-americanos, sediados nas universidades americanas ou em suas instituições de origem. Acrescentaria ainda que a grande questão levantada pelos estudos culturais reside na associação entre teoria e política, a partir da necessidade de ser a prática teórica uma forma de intervenção do intelectual - o conceito é de Stuart Hall - no momento histórico.

Ao longo desses últimos anos, a Abralic tem atravessado momentos de crescimento e de debate teórico, em virtude da presença de posições distintas diante do seu objeto e sua metodologia. Essa diferença epistemológica tem provocado certa diáspora entre os seus membros, principalmente entre aqueles que defendem o campo disciplinar segundo critérios de valor estético e literário, pois o próprio nome da disciplina assim os exige. Ou a preocupação em considerar o campo da literatura comparada segundo parâmetros fixados pelas regras de ordem ontológica e fundamentalista. Os dissidentes dessa posição, compreendidos entre aqueles que acreditam na abertura interdisciplinar e no saldo positivo da crítica cultural, conseguem enxergar o grau de conservadorismo que se instalou na maioria dos discursos representativos da outra vertente.

\section{Margens latinas}

O projeto editorial de algumas editoras universitárias como a UFRJ e a UFMG contribuíram, no decorrer desses anos, para a recepção cada vez mais vigorosa dos textos relativos aos teóricos da crítica cultural, assim como para a aproximação entre o pensamento teórico brasileiro e o latino-americano, seja via Estados Unidos, seja por via direta. Esse avanço teve como uma das motivações iniciais o convite feito a pesquisadores da área, com o respaldo das associações literárias, dos cursos de pósgraduação e dos intercâmbios internacionais. O Centro Interdisciplinar de Estudos Contemporâneos (CIEC) e o Programa Avançado de Cultura Contemporânea (PACC) órgãos de pesquisa da Faculdade de Comunicação da UFRJ, dirigidos por Heloísa Buarque de Hollanda - , assim como a editora da UFRJ, deram o primeiro passo para a abertura latina, e para a crítica cultural, com a publicação de obras significativas de Néstor Canclini, Beatriz Sarlo, Fredric Jameson, Martín-Barbero, Jean Franco, Edward Said, entre outros. Esse projeto acompanhou, nos anos de 1990, a realização de vários seminários, dentre os quais o intitulado "Artelatina", que em 2000 reuniu no Fórum de Cultura, especialistas em comunicação, artes plásticas e crítica cultural. Dentro dessa perspectiva, é possível considerar que os estudos culturais - graças ao incentivo e participação efetiva de Silviano Santiago - se firmou no Rio de Janeiro de forma ímpar,

\footnotetext{
${ }^{6}$ Cf. SOUZA, Eneida Maria de. Crítica cult. Belo Horizonte: Editora UFMG, 2002.
} 
tendo sido acompanhado por Belo Horizonte, Salvador, PortoAlegre e Florianópolis, entre outras instituições.

Os vários congressos promovidos pela Abralic revelaram igualmente a preferência pelo debate cultural, iniciando-se com escritores e teóricos latinoamericanos, como Ricardo Piglia, Beatriz Sarlo, Josefina Ludmer, Ana Pizarro, ao mesmo tempo que recebia Fredric Jameson, Homi Bhabha, Stuart Hall, Spivak, Andréas Huyssen, Walter Mignolo, Alberto Moreiras, Paul Gilroy, GeorgeYúdice, Ernesto Laclau, Nelly Richard, Hugo Achugar, dentre outros. É notório acrescentar que a maioria dos conferencistas convidados para as sessões de abertura dos eventos representavam linhas de crítica cultural, fator este que reforça o projeto teórico e político das diretorias da Associação. O intercâmbio teórico recebe um impulso até então inexistente, com a conseqüente tradução de livros de crítica cultural, desta vez por iniciativa de editoras universitárias, em que se sobressai a Editora UFMG, dirigida por Wander Melo Miranda, desde 1998. A repercussão desse avanço editorial se evidencia na ótima recepção por parte da classe universitária de obras de autores como Homi Bhabha e Stuart Hall, considerados best-sellers da Casa. Por atingir número variado de leitores não circunscritos às faculdades de letras, esses textos de crítica cultural permitiram a ampliação e a relativização das questões identitárias, étnicas, de gênero, além de incentivarem a produção teórica acadêmica. Com o acesso facilitado à produção ensaística latino-americana, o discurso crítico nacional se encontra em condições de construir um pensamento não globalizante do imaginário latinoamericano, pela sistematização de conceitos comuns e pela deliberação de compartilhar saberes com outras culturas até então distantes e desconhecidas. É forçoso lembrar que o projeto editorial da UFMG coincide com o trabalho realizado pela pós-graduação em letras - na área de literatura comparada -, que nos seus 20 anos de existência, é considerada uma das mais conceituadas do país.

Gostaria de mencionar, finalmente, dois projetos que envolvem o Brasil e a Argentina, que são o da Revista de Cultura Margens/Márgenes, iniciado em 1997, e sob a direção de Silviano Santiago e Wander Melo Miranda, e o projeto da Coleção Vereda Brasil, também entre o Brasil e a Argentina, que propõe a publicação de livros de autores brasileiros naquele país vice-versa. $\mathrm{Na}$ primeira proposta, é forçoso assinalar que se trata de uma publicação pioneira quanto à colaboração de pesquisadores argentinos e brasileiros, na tentativa de estabelecer um diálogo que poderia ter sido efetivado há mais tempo, sem falar no convívio ainda precário com os demais países da América Latina. A proposta cultural da revista não se fecha nas questões latinas, mas se envolve com os temas da atualidade, trazendo articulistas de renome internacional e revelando outros de pouca circulação entre nós. Os frutos desse programa interinstitucional - UFMG, UFBA, UBA, Universidade de Mar del Plata e, mais recentemente, a Universidade de Roma Tor Vergata - têm revertido em ganho teórico e em avanço necessário para o debate político e cultural que se realiza não só academicamente como junto à comunidade leiga.

Uma advertência contudo deverá ser feita: solicita-se muita cautela do crítico ao refletir sobre os discursos que compõem a história da crítica comparada e cultural no Brasil. Que este não seja nunca entendido como objeto descartável, efêmero e destituído de fundamento. Não se trata de afirmar como os cultores do modernariato que o presente já é passado, ou considerar como lembrança o que ainda não foi nem assimilado ou entendido pela maioria dos leitores. A rapidez e a facilidade com que são desprezados autores ou teorias em favor de novidades ou de repetições do já visto impedem o exercício paciente e cuidadoso da crítica, a ser efetuada por meio da leitura dos silêncios e das fraturas teóricas, das ruínas discursivas que seduzem a revisão do 
objeto. O trabalho de constituição da memória da crítica cultural em ritmo latino ainda está para ser iniciada, desafio que poderá ser enfrentado pela nova geração de críticos, responsável pela continuação - ou ruptura- dos caminhos tortuosos e instigantes criados por várias gerações.

\section{Babel, o filme}

Tendo em vista a simultaneidade das cenas montadas no filme Babel, com o objetivo de apresentar a atuação de diferentes personagens em distintos países e culturas, embora estejam ligadas por um acontecimento comum, haveria um conceito único de modernidade que os uniria? Qual o grau de semelhança e de diferença entre distintas feições do moderno vivenciado pelas personagens inseridas na vida urbana do Japão, no deserto de Marrocos, na fronteira entre o México e os Estados Unidos? A constatação de ser a película uma das grandes reflexões sobre a tênue fronteira que separa os povos, os seres humanos, sobre um lance do acaso que irrompe e provoca distúrbios incontroláveis, não estaria ai expressa a idéia de uma modernidade global, totalitária e perversa?

A análise do filme se concentra nas diferentes modalidades do conceito de modernidade, na discussão do multiculturalismo como representação contemporânea dos efeitos que a globalização econômica tem provocado na atualidade diante de países tão diferentes do ponto de vista econômico, social, cultural e político. Autor de Amores brutos, de 2000 e de 21 gramas, de 2003, Alejandro González Iñarritu completa a trilogia, em 2006, com Babel, realizando a película com produção mexicana e norteamericana. O roteiro é de Guillermo Arriaga.

O título do filme remete ao mito bíblico, contido no Gênesis, da torre de Babel. A confusão, gerada pela tentativa dos homens construírem uma torre capaz de alcançar o céu, termina com o impedimento, por deus, de sua construção. A ação, considerada manifestação de soberba da população, resulta no desentendimento entre os homens, que começam, a partir desse momento, a falar idiomas diferentes. O filme trata do tema da incompreensão entre as personagens e entre culturas. Refere-se, ainda, ao sentido intraduzível do título, processo almejado pela política da globalização para facilitar a compreensão entre povos de línguas distintas. Por essa razão, coincide com a fase prébabel, quando a língua era uma só e todos se entendiam. Ironicamente, o título endossa e nega o tema da incomunicabilidade existente no filme, nega e endossa a sintonia criada com o espectador. Torres de Babel, de Jacques Derrida, ${ }^{7}$ discorre sobre a intraduzibilidade do nome, a impossibilidade de tradução. O nome é comentado, parafraseado, mas não traduzido. Outra associação merece ser feita entre o filme e as torres gêmeas de Nova York, abatidas pelos muçulmanos, em 2001, acontecimento responsável pelas mudanças significativas no sistema de controle e policiamento da esfera mundial. As torres de Tóquio, apresentadas como ícones da modernização, se configuram para o espectador como a tentativa de vencer, igualmente, pela tecnologia, a aspiração divina de atingir o céu, de demonstrar poderes e desafios do homem diante da máquina. Do ponto de vista arquitetônico, as torres seria o simulacro do progresso urbano e comercial americano, entendido como espelho das potências pós-modernas.

A montagem simultânea das cenas segue o modelo dos filmes anteriores, em que se processa a narração fragmentada, ao romper com a cronologia tradicional do discurso cinematográfico: após o anúncio da cena, a apresentação rápida das mesmas, volta-se à elucidação do enredo aí suspenso. As fronteiras fílmicas da montagem são abolidas,

\footnotetext{
${ }^{7}$ DERRIDA, Jacques. Torres de Babel. Tradução: Júnia Barreto. Belo Horizonte: Editora UFMG, 2002.
} 
sugerindo o movimento rápido e dinâmico das ressonâncias da globalização nos variados países, o corte cinematográfico como apropriação das técnicas de captação de noticias televisivas que se realizam no momento real em que estas acontecem. A visão condensada dos acontecimentos dirige o olhar do espectador para a rapidez com que se transita de um lugar a outro do globo, lugares distanciados geograficamente, mas que se aproximam de forma virtual pela ação da câmera. As peças, ao longo da película, vão-se recompondo, como um quebra-cabeças, um jogo de armar, movidas por um fio invisível que comanda o espetáculo, já com cartas marcadas para o resultado e o final do jogo. Os detalhes que associam as cenas entre si são mostradas de forma contrastiva, com o intuito de apontar diferenças de ordem cultural e ao mesmo tempo, semelhanças de comportamento e desejos inerentes a todo ser humano. No Marrocos, o filho mais novo é o escolhido pelo pai, como o mais corajoso e hábil para substituí-lo. É o autor do disparo da espingarda comprada pelo pai de um amigo. Em fase de iniciação sexual, observa, como voyeur, a irmã trocar de roupa, diálogo proibido realizado pela relação esquiva entre olhar e ser olhado. No Japão, a jovem surda-muda ensaia a comunicação dificil com os rapazes pela exibição do corpo, pela experiência das drogas. Em ambas situações registra-se a incomunicabilidade como tema recorrente, assim como de das outras cenas envolvendo outras personagens.

O enredo, de complexa urdidura, pode ser resumido de forma também fragmentada e ser entrecortado por interpretações. A experiência da morte é o tema que congrega todas as cenas. Vivenciada de maneiras diferentes, ela é acompanhada do ritual de iniciação pelo qual as personagens entram no processo de aprendizagem relativa à falta e à morte. Para a atualização desse ritual, situações de perigo, isolamento e sofrimento concorrem para a passagem a outro nível, da criança para o adulto, do celibatário para o casado, da natureza para a cultura, da saída da casa paterna para o mundo. $\mathrm{O}$ casal de americanos convive com a proximidade da morte iminente, a perda de sangue, a dor, o alívio do sofrimento pela ação da mulher marroquina, silenciosa e que com o remédio, o fumo, revela saídas alternativas e naturais para a cura e a criação de uma relação de afeto entre as pessoas. O jovem marroquino, ao atingir a americana, é jogado para outro nível de responsabilidade social, confessa ao pai o crime e se esconde dos policiais. A japonesa surda-muda, em fase de iniciação sexual, se entrega ao policial em sua própria casa. Os filhos do casal de americanos saem pela primeira vez de casa sem os pais, atravessam a fronteira dos Estados Unidos e entram em contato com os costumes mexicanos durante o casamento do filho da babá, entre eles a decapitação da galinha, a visão do sangue escorrendo, o convívio com o estranho. Na volta, a fuga de carro com o sobrinho da babá, pela madrugada, sendo perseguidos pelos guardas e vivenciando a experiência do perigo e da morte. A última imagem das crianças é a do abandono no deserto, na fronteira, entregues ao total desamparo.

A primeira cena do filme, a venda de uma arma por um camponês marroquino, é feita na presença do comprador e dos dois filhos. A arma teria a função de matar os chacais, perigosos adversários das ovelhas. Deflagra os acontecimentos futuros e funciona como elo que interliga as cenas de todo o filme. As quatro narrativas se conjugam, representadas por quatro paises, Marrocos, Japão, Estados Unidos e México, e três continentes: América do Norte, África e Ásia. Nesta primeira cena, a paisagem é o deserto de Marrocos, com suas montanhas e caminhos tortuosos, onde se pratica a pecuária, a criação de ovelhas, atividade passada de pai para filho. O comércio informal é operado por uma economia agrária, pela troca de produtos entre os membros da comunidade. A venda da espingarda irá gerar a corrente futura que culminará com a necessidade de descobrir o primeiro proprietário da aram, para se encontrar o autor do crime. O ambiente, despojado e aberto, contrasta com a modernidade excessiva de 
Tóquio, da metrópole pós-moderna, caracterizada pela alta tecnologia do primeiro mundo. Trata-se de um espaço que escapa da racionalidade moderna, dos domínios específicos do Estado-nação, constituindo-se como lugar vazio, capaz de provocar distúrbios inesperados e metamorfoses.

Nesse deserto ocorre a cena que envolve o casal de americanos em viagem de turismo em Marrocos, num ônibus que reúne pessoas de várias nacionalidades. $\mathrm{O}$ motivo da viagem é extremamente particular, pois serviria para tentar esquecer o drama do casal pela perda do filho mais novo, embora a depressão da mulher e precariedade higiênica do lugar, aos seus olhos, a impedisse de usufruir o passeio. Inconsolável, não se sente bem em Marrocos, e esse sentimento se manifesta pelo alto grau de incomunicabilidade entre eles. $\mathrm{O}$ casal de filhos permanece na Califórnia, sob os cuidados da babá, de origem mexicana, que espera a volta dos patrões para ir ao casamento do filho no México, numa cidade fronteiriça com os Estados Unidos. $\mathrm{O}$ filho mais novo da família marroquina, ao demonstrar para o irmão sua habilidade no manejo com a arma, uma espingarda Winchester, atira a esmo e por acaso atinge a americana que viaja no ônibus. Com a ajuda do rapaz que trabalha no ônibus, consegue-se chegar ao povoado onde mora o ajudante.

$\mathrm{Na}$ cidade de Tóquio, com suas torres, prédios iluminados e coloridos, vislumbra-se o espetáculo da cidade pós-moderna, luxuosa, marcada por uma cultura heterogênea e em confronto com os valores tradicionais. $\mathrm{O}$ apartamento da jovem surdamuda revela o conforto e a natureza limpa e despojada dos interiores, traços do gosto burguês, do excesso de tecnologia que resulta na carência de adornos e enfeites excessivos. A carência se metaforiza nos comportamentos regrados, nos relacionamentos frágeis e na incomunicabilidade entre pai e filha, acentuada após o suicídio da mãe. A jovem se comunica com os outros através de sinais, da escrita e do corpo. O diálogo um pouco efetivo se dá com o porteiro do prédio, mediador entre o fora e o dentro, entre a esfera semidoméstica e a pública. Este lhe passa os recados e possibilita o encontro entre a jovem, a policia e o pai. Por um jogo espelhado das histórias, a jovem se expõe sexualmente para os rapazes, num gesto de rebeldia, ironia e afastamento. No caso do encontro com o policial, ao se desnudar, e se entregar a ele, o relacionamento, embora estranho e revelador da falta de entrosamento com outras pessoas de seu meio e idade, responde pelo futuro encontro com o pai. A cena representa, entre outras significações, a condensação da figura do pai na do policial, o que motiva a realização do desejo de se unir ao pai, considerando essa união como forma de restaurar o equilíbrio familiar e social. Em Marrocos, a promiscuidade familiar incita o desejo sexual entre irmãos e acende, de forma natural, a sexualidade reprimida, demonstrando a necessidade de romper fronteiras de ordem familiar. Este núcleo se mostra tão fechado, em virtude das poucas opções de conhecimento do outro, que incita à relação incestuosa, o reforço da concepção tradicional de família. Espelhadas igualmente são as situações de perda entre o casal americano, ou seja, a perda do filho, e a jovem japonesa, a perda da mãe.

Na Califórnia, outra cena: a babá dos filhos do casal americano, que se prepara para ir ao casamento do filho no México. Resolve levar as crianças à festa, na impossibilidade de deixá-las com alguém, e diante da permanência dos patrões em Marrocos. O ritual do casamento, de natureza festiva e se associa ainda ao ritual de passagem, não só do ponto de vista das crianças, mas em relação aos noivos. A passagem de um estado civil para outro é comemorada com festa e música, e com a presença de amigos e familiares. É o coroamento da concepção de família nos moldes tradicionais. Percebe-se a cena por meio não da economia afetiva, mas do excesso, representado pelo grande número de parentes, de alegria e descompromisso com as 
ações. O sinal desse descompromisso se verifica no gesto do sobrinho da babá, ao lançar tiros para o alto, como sinal de congraçamento. $\mathrm{O}$ mesmo descompromisso resulta em tragédia, por ocasião do disparo feito pelo jovem marroquino. $\mathrm{Na}$ cena mexicana, acredita-se ainda na integração familiar como sustento para a preservação dos valores tradicionais de união e solidariedade. A necessidade de integração da família irá funcionar, no final do filme, como saída um tanto provisória imposta pela incomunicabilidade vivida pelas personagens.

$\mathrm{Na}$ busca pelo proprietário da arma cujo disparo atingiu a americana, policiais procuram o pai da jovem japonesa. Doada pelo japonês em viagem turística ao Marrocos ao seu guia, este a vende aos pais dos meninos. Na busca em Marrocos pelos criminosos, o jovem confessa ter sido ele o autor dos disparos. No final, a Embaixada Americana resgata o casal e a mulher se salva. O possível ato de terrorismo cometido em Marrocos é desfeito pela confissão do jovem marroquino, que, de mãos erguidas, e diante da troca de tiros com os policiais, ter sido ele o autor do disparo.

O drama vivido pelas personagens retoma o drama existencial e político contemporâneo, no qual o acaso é o deflagrador dos acontecimentos, no lugar de uma ação premeditada e objetiva. $\mathrm{O}$ acaso, as coincidências e a impossibilidade de controle das situações traduzem a imprevisibilidade da sociedade contemporânea. Aquilo que não se pode prever. Assim, quanto mais controle estatal, mais se constata a presença das linhas de fuga, da inserção do outro no sistema. O sentimento de culpa, mesmo tendo sido assumido pelo jovem, deixa de ser um dado a ser considerado pelo espectador. Da mesma forma que o autor do crime não é o primeiro possuidor da arma, uma vez que se dissolve a idéia de relação entre o crime e o proprietário da arma, pelo descontrole que o objeto e a sua trajetória acarretam. A arma entra no sistema simbólico e abstrato das trocas. Rompe-se com a relação de causa-efeito, em virtude de não existir uma causa premeditada do crime. Os proprietários da arma e os autores do crime perdem a função a eles atribuídos. Essa responsabilidade é parte do sistema, com sua perversidade e o caráter aleatório das ações, atitudes próprias do descontrole que se processa em cadeia. A gratuidade das ações provoca o efeito dominó, o efeito bola de neve. À semelhança do processo de globalização, onde uma ação acontece em determinado país e ecoa nos outros de forma imediata. Tiros trocados entre a família de Marrocos e os policiais entram no processo de descontrole e começam a liquidar inocentes. As invasões dos Estados Unidos no Afeganistão e no Iraque confirmam essa gratuidade das ações, o jogo perverso que desloca a culpa do sistema político hegemônico para as sociedades consideradas atrasadas e movidas pela irracionalidade.

As situações de total impotência diante das leis são vivenciadas pela babá mexicana, presa na fronteira do México com os Estados Unidos por estar ilegalmente no país, e pelo autor dos disparos, no Marrocos. A babá, em plena zona desértica, perde os filhos, ao substituir a mãe doente, perde o emprego e a possível cidadania americana. $\mathrm{O}$ espaço da punição é o deserto mexicano-americano, fronteira que marca o signo da indecisão e do heterogêneo. Entendido como espaço de exceção, de perigo, de diferença em relação aos espaços urbanos, a fronteira separa territórios, apresentando-se como espaço livre para se cumprir qualquer tipo de lei. Em ambos lugares, o deserto marroquino e o de fronteira, cria-se um estado de exceção - a vida nua, segundo interpretação de Giorgio Agamben, o homo sacer - situação quando o criminoso não tem com o que defender e é julgado sem escrúpulos, por não ter igualmente direito de defesa. Quando julgado por um delito, o homem sacro pode ser morto sem que isso constitua um homicídio, ou execução, ou condenação. Campos de concentração, prisioneiros acusados de terem realizado ações terroristas, infrações às leis de imigração, todos essas pessoas são perseguidas por serem dotadas de identidades 
duvidosas. Perderam tudo e, como refugiados, não se sabe que lei aplicar a eles: "O estado de exceção, logo, não é tanto uma suspensão espaço-temporal quanto uma figura topológica complexa, em que não só a exceção é a regra, mas até mesmo o estado de natureza e o direito, o fora e o dentro transitam um pelo outro. É justamente nesta zona topológica de indistinção, que deveria permanecer oculta aos olhos da justiça, que nós devemos tentar em disso fixar o olhar". 8

As observações finais desta análise são dirigidas ao encontro das personagens que se unem pelo afeto, pela criação de um elo comum que rompe com $o$ comportamento usual, reintegra o relacionamento e desconstrói imposições de âmbito racional e distanciado. A americana se encontra nesse gesto afetivo com o marido, quando é por ele ajudada a fazer as necessidades fisiológicas. Ou quando a mulher marroquina alivia a sua dor, aproximação que se realiza pela aspiração, do fumo da substância por ela preparada. A união da família marroquina pela dor da morte do filho mais velho obriga o outro a se confessar. $\mathrm{O}$ encontro no alto da varanda do apartamento, em Tóquio, da jovem com o pai, com vista para a paisagem noturna e iluminada, sugere a conquista desse afeto perdido. São os descompassos da modernização conservadora e desenfreada, apresentadas nas suas inúmeras dimensões e diferenças, o preço a pagar pela perda de valores humanitários, submersos na guerra cotidiana do trabalho e da racionalidade. Babel representa cenas alegóricas que remetem tanto para as desigualdades e descompassos entre os povos quanto da imagem do acaso como estratégia para a dominação do mundo pelos paises que ainda impõem seu poder hegemônico diante dos paises periféricos. Nações que, contudo, se desintegram e se fragmentam na luta pelo domínio cego das demais.

\footnotetext{
${ }^{8}$ AGAMBEN, Giorgio. Homo sacer. O poder soberano e a vida nua. Belo Horizonte: Editora UFMG, 2002. p. 43.
} 